\title{
ANALISIS KINERJA JALAN TENGKURUK PERMAI DENGAN MIKROSIMULASI PEMINDAHAN TERMINAL DAN PARKIR BADAN JALAN
}

\author{
Taharudin ${ }^{1 *}$, Melawaty Agustien ${ }^{2)}$, dan Joni Arliansyah ${ }^{2)}$ \\ 1) Tenaga Ahli CV. Archi Engineering, Jl. Jambu II No 115 RT 07 Kelurahan Watervang, Lubuk Linggau \\ 2) Jurusan Teknik Sipil FT UNSRI, Jl. Raya Prabumulih - Km 32 Indralaya, Ogan Ilir, Sumsel
}

\section{Abstract}

Tengkuruk Permai street is currently used for city transportation terminals, on street parking, access and exit to 16 Ilir market parking lot (off street parking), entrance to Ampera Bridge, passenger access to LRT stations and Skate Park. The various functions of this street caused the reduction in street service levels at certain hours and become a congestion point in Palembang city. This study aims to obtain the results of the analysis of Tengkuruk Permai's street performance in the scenario conditions of terminal relocation and on street parking. The data were collected directly by measuring and enumeration then micro-simulated with the Vissim software. Vissim microsimulation modeling is carried out in existing conditions and scenarios by combining the 3 (three) floors parking building construction plans, city transport routes, Tengkuruk Permai street which has been cleared of on street parking and terminals, street networks around the research location and intersection arrangements concurrently. The street performance analysis uses the calculation of the $\mathrm{V} / \mathrm{C}$ ratio, where the calculation of the street capacity uses the Vissim microsimulation output such as speed, density and volume obtained in the link of segment evaluation menu. Capacity determination is using the calculation of relation of flow (q), velocity (v) and density (k). The scenario of relocating the city transport terminal and street parking to the 3 (three) floors parking building plan at 16 Ilir market parking lot can increase the capacity of Tengkuruk Permai Street from 1087,88 pcu/hour/direction to $2295.15 \mathrm{pcu} /$ hour/direction and improve the service level from level E to level A.

Key Words: level of service, microsimulation, parking, V/C Ratio, Vissim.

\section{PENDAHULUAN}

Pasar 16 Ilir merupakan pasar tradisional terbesar di Kota Palembang. Pasar ini berbatasan dengan Jalan Tengkuruk Permai yang saat ini 2 (dua) lajurnya digunakan untuk terminal angkutan kota, parkir badan jalan, akses keluar masuk ke pelataran parkir Pasar 16 Ilir, jalan masuk ke Jembatan Ampera, akses penumpang ke stasiun LRT dan Skate Park. Beragamnya fungsi jalan Tengkuruk Permai mengakibatkan kompleksitas lalu lintas sehingga pada jam-jam tertentu menimbulkan penurunan tingkat layanan jalan sehingga menjadi salah satu titik kemacetan di kota Palembang.

Parkir yang efektif dan efisien dapat meningkatkan efisiensi arus lalu lintas secara signifikan (Małecki, 2018). Faktor parkir badan jalan dan penghentian kendaraan merupakan faktor terpenting dalam mengurangi kecepatan (Munawar, 2011). Terjadi pengurangan kapasitas jalan sebesar $6 \%, 10 \%$, dan $16 \%$ akibat manuver kendaraan keluar masuk ruang parkir badan jalan, atau setara dengan 10, 20, dan 30 kendaraan per jam (Portilla, A. I, Orena, B. A., Berodia, J. L. M., \& Diaz, F. J.
R., 2009). Dengan mikrosimulasi Vissim 5.3, disimpulkan bahwa menghapus parkir di jalan dapat mengurangi tundaan rata-rata $12 \mathrm{detik} / \mathrm{kendaraan}$ (32\%) dan meningkatkan kecepatan $5 \mathrm{~km} / \mathrm{jam}$ (24\%) (Sugiarto \& Limanoond, T., 2013).

Penelitian-penelitian di atas menjelaskan dampak buruk parkir badan jalan terhadap kinerja jalan sehingga diperlukan penanganan. Penanganan yang dapat dilakukan adalah memindahkan parkir badan jalan ke pelataran parkir atau ke gedung parkir. Berdasarkan pengamatan ketersediaan lahan di lokasi penelitian, pemindahan parkir badan jalan dan terminal dapat dilakukan ke pelataran parkir Pasar 16 Ilir. Penggabungan fungsi ini membutuhkan fasilitas parkir baru yang mampu menampung kapasitas parkir badan jalan, terminal dan parkir pelataran Pasar 16 Ilir.

Kinerja Jalan Tengkuruk Permai digunakan sebagai parameter keberhasilan skenario pembangunan fasilitas parkir tersebut karena jalan ini menerima dampak lalu lintas akibat keluar masuk kendaraan yang melakukan parkir. Indeks Tingkat Pelayanan (ITP) diperoleh dengan 
membandingkan antara volume dan kapasitas jalan yang dihasilkan mikrosimulasi Vissim. Menurut (Pribadi, 2017), penggunaan metode mikrosimulasi Vissim menghasilkan hubungan kecepatan dan volume yang lebih mendekati hasil survei dibandingkan hasil MKJI 1997.

Hubungan kecepatan dan volume merupakan dasar perhitungan kapasitas jalan. (Munawar, A. \& Yulianto, R. A., 2017) menggunakan metode mikrosimulasi Vissim untuk menentukan nilai kapasitas jalan bebas hambatan di Jalan Tol Cawang-Tomang-Cengkareng (CTC) $\mathrm{Km} \mathrm{5,4}$ dan Jalan Tol JKT-CKP (JKT-CKP) Km 38. Metode ini dapat diaplikasikan di lokasi lain yang mempunyai kemiripan karakteristik lalu lintas.

\section{METODOLOGI}

Penelitian ini bertujuan untuk mendapatkan kinerja Jalan Tengkuruk Permai berdasarkan hasil analisis luaran mikrosimulasi Vissim pada kondisi skenario pemindahan terminal angkutan kota dan parkir badan di Jalan Tengkuruk Permai ke pelataran parkir Pasar 16 Ilir dengan skenario membangun fasilitas gedung parkir.

Penelitian berlokasi di Jalan Tempuruk Permai yang berdekatan dengan Pasar 16 Ilir, Masjid Agung, Museum Sultan Mahmud Badaruddin II, Monumen Penderitaan Rakyat (MONPERA), Stasiun Light Rail Transit (LRT), Terminal Type C dan Skate Park Ampera (Gambar 1). Jalan ini secara administratif berada di Kelurahan 19 Ilir, Kecamatan Bukit Kecil, Kota Palembang.

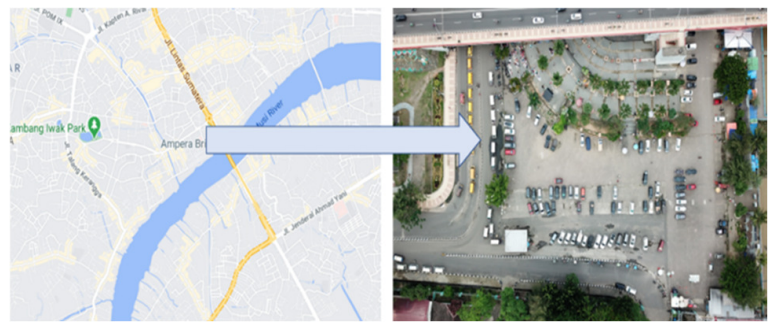

Gambar 1. Lokasi penelitian

\section{Pengumpulan Data}

Pengumpulan data dilakukan pada tanggal 28 Maret 2020 (Sabtu), 31 Maret 2020 (Senin) dan 1 April 2020 (Rabu) pukul 06.00-18.00 WIB bersamaan dengan waktu pencacahan volume kendaraan. Data yang dikumpulkan, adalah:

\section{a. Data Geometrik Jalan dan Pelataran Parkir}

Data geometrik diambil menggunakan pengukuran topografi menggunakan Theodolith Total Station dengan sistem poligon terbuka. Tahap ini juga merekam arah, jumlah dan lebar lajur jalan, jumlah dan lebar jalur pejalan kaki. Pengukuranpengukuran detail seperti dimensi Satuan Ruang Parkir (SRP) menggunakan meteran.

\section{b. Volume Kendaraan}

Volume kendaraan dikumpulkan dengan menghitung secara manual kendaraan yang melintas di titik pantau dengan mengklasifikasikan berdasarkan Pedoman Survei Pencacahan Lalu Lintas dengan Cara Manual, Pd.T-19-2004-B (Departemen_Permukiman_dan_Prasarana_Wilayah , 2004). Kendaraan diklasifikasikan menjadi Sepeda Motor (MC), Kendaraan Penumpang Ringan (LV), Medium sampai Heavy Vehicle (MHV) dan Large Truck (HV). Volume kendaraan direkam dalam formulir yang mengakumulasi volume kendaraan setiap 15 menit.

\section{c. Kecepatan Sesaat Kendaraan}

Kecepatan sesaat (spot speed) diukur menggunakan speed gun di lokasi yang lurus dengan sampel 60 kendaraan tiap 1 jam untuk masing-masing arah.

\section{d. Volume dan Durasi Parkir Pasar 16 Ilir}

Volume dan durasi di pelataran parkir Pasar 16 Ilir dikumpulkan dengan mencatat nomor kendaraan, waktu masuk dan keluar semua jenis kendaraan dan mengklasifikasikan dalam 3 (tiga) kategori yakni motor, mobil pribadi dan truk kecil.

\section{e. Volume dan Durasi Parkir Badan Jalan}

Volume dan durasi parkir badan jalan dikumpulkan dengan dengan mencatat nomor kendaraan yang parkir di badan jalan dengan berpatroli setiap interval waktu 30 menit.

\section{f. Volume dan Waktu Tunggu Angkutan Kota}

Data volume angkutan kota dikumpulkan dengan menghitung angkutan kota yang masuk ke terminal, mencatat nomor kendaraan dan merekam waktu masuk dan keluar angkutan kota.

\section{Pengolahan Data Primer}

Data primer yang diperoleh melalui pengukuran dan pencacahan yang terdiri dari volume kendaran, volume parkir, kecepatan kendaraan, durasi parkir dan waktu tunggu angkutan kota diolah dengan perangkat lunak Microsoft Excel.

\section{Skenario Pemindahan}

Skenario pemindahan terminal dan parkir badan jalan dilakukan ke pelataran parkir Pasar 16 Ilir karena hanya lokasi inilah yang paling 


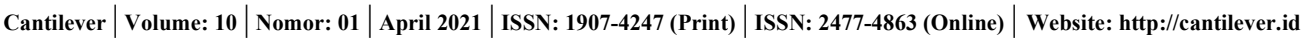

Taharudin, dkk. | Analisis Kinerja Jalan Tengkuruk Permai dengan Mikrosimulasi Pemindahan Terminal dan Parkir Badan Jalan

realistis akibat keterbatasan lahan. Berdasarkan data-data yang telah disampaikan sebelumnya penggabungan 3 (tiga) aktivitas membutuhkan 334 SRP mobil penumpang dan 263 SRP Motor. Pemenuhan kebutuhan SRP tersebut dilakukan dengan skenario pembangunan gedung parkir 3 (tiga) lantai dan penempatan jalur khusus yang terdiri 3 (tiga) lajur untuk angkutan kota yang mengarah ke Pasar 16 Ilir. Skenario juga membuat pola sirkulasi baru yakni akses masuk kendaraan penumpang berada di pintu keluar eksisting sedangkan pintu keluarnya ke Jalan Sultan Mahmud Badaruddin II. Penempatan angkutan kota terpisah dari parkir kendaraan penumpang dan jalur sirkulasinya dibuat jalur khusus. Penempatan pintu masuk angkutan kota sama dengan kendaraan penumpang namun pintu keluarnya di Jalan Pasar 16 Ilir (pintu masuk eksisting). Skema sirkulasi tercantum dalam Gambar 2.

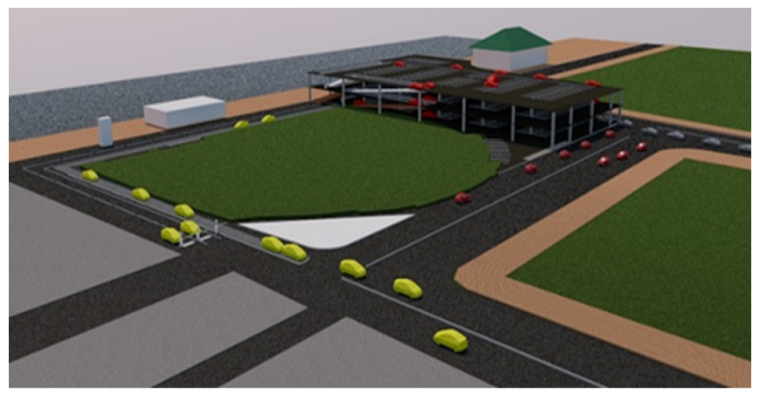

Gambar 2. Skenario Gedung Parkir dan sirkulasinya

\section{Pemodelan Mikrosimulasi Vissim}

Pemodelan dilakukan pada kondisi eksisting dan skenario pemindahan terminal dan parkir badan ke pelataran parkir dengan menggunakan perangkat lunak Vissim 8. Pemodelan eksisting digunakan untuk mengetahui kinerja jalan awal sehingga dapat dilakukan perbandingan dterhadap hasil penanganan. Model Vissim perlu dilakukan proses kalibrasi dan validasi agar model mencerminkan kondisi lalu lintas sesungguhnya. Proses kalibrasi dilakukan dengan mencoba-coba nilai-nilai tertentu pada menu perilaku berkendara (driving behaviour) pada fungsi average standsill distance dan additive part distance. Validasi model menggunakan uji statistik Geoffrey E. Havers (GEH) dilakukan jika nilai perbandingan antara volume kendaraan luaran model Vissim dan hasil pencacahan di lokasi penelitian melampaui nilai $75 \%$ sebagai ambang batas minimum kalibrasi (toleransi 15\%). Nilai uji GEH diterima jika bernilai kurang dari 5 sesuai dengan rentang nilai GEH dan tingkat penerimaannya yang dikeluarkan oleh NCHRP
Report 765:Analytical Travel Forecasting Approaches for Project-Level Planning and Design seperti tercantum dalam Tabel 1 (NCHRP, 2014).

Tabel 1. Rentang Nilai GEH dan Tingkat Penerimaannya

\begin{tabular}{ccl}
\hline No & Nilai GEH & \multicolumn{1}{c}{ Kriteria } \\
\hline 1 & GEH $<5$ & Diterima dengan baik \\
2 & $5,0 \leq \mathrm{GEH} \leq 10,0$ & $\begin{array}{l}\text { Perhatian, kemungkinan model salah } \\
\text { atau data buruk } \\
\text { Peringatan, kemungkinan besar } \\
\text { model salah atau data buruk }\end{array}$ \\
3 & GEH $>10,0$ & \\
\hline
\end{tabular}

Nilai GEH diperoleh dengan:

$$
G E H=\sqrt{\frac{2(m-c)^{2}}{m+c}}
$$

dengan:

$$
\begin{aligned}
& \mathrm{m}=\text { volume luaran model (kendaraan/jam) } \\
& \mathrm{c}=\text { volume hasil pencacahan (kendaraan/jam) }
\end{aligned}
$$

Pemodelan kondisi eksisting yang telah valid dijadikan sebagai model dasar (base model) untuk membangun mikrosimulasi kondisi skenario dengan langkah-langkah sebagai berikut:

a. Memasukkan gambar latar (Background)

b. Membuat Links dan Connectors

c. Mendefinisikan Vehicle Type

d. Membuat Vehicle Composition/relative flow

e. Melakukan Vehicle Input

f. Membuat Distribution Desired Speed

g. Membuat Time Distribution

h. Melakukan Traffic Distribution (Routing)

i. Memasang Signal Kontrol

j. Membuat Parking Lot

k. Membuat Evaluation

1. Menjalankan Vissim dan merekam hasil running Vissim dalam format Microsoft Exel

\section{Penentuan Kapasitas}

Penentuan kapasitas jalan pada kondisi eksisting dan skenario menggunakan mikrosimulasi Vissim dilakukan dengan menganalisis hubungan kerapatan, kecepatan dan volume yang merupakan luaran menu link segment evaluation. Berdasarkan hubungan arus, kecepatan dan kerapatan (q=vk) dimana kecepatan berbanding lurus dengan kerapatan, dibangun grafik hubungan antara kerapatan dan kecepatan dengan pendekatan linier, ekponensial dan logaritmik menggunakan bantuan perangkat lunak Microsoft Exel. Grafik hubungan ini menghasilkan model matematis dan nilai koefesien determinasi $\left(\mathrm{R}^{2}\right)$. Model matematis yang digunakan dalam proses selanjutnya adalah model dengan nilai koefesien determinasi tertinggi.

Model matematis terpilih kemudian dioperasikan dengan memasukkan variasi kerapatan dimulai 
angka 0 sampai angka yang dibutuhkan untuk mengetahui nilai kecepatan maksimum menuju hasil hampir 0 (asimptotis). Penentuan kapasitas ditentukan dengan menggunakan hubungan arus, kecepatan dan kerapatan dimana arus merupakan hasil perkalian kecepatan dan kerapatan (q=vk). Berdasarkan persamaan ini diperoleh nilai arus $(q)$ yang merupakan hasil perkalian antara kecepatan (v) hasil operasi model matematis terpilih dan nilai variasi kerapatan (k). Nilai kapasitas ditetapkan pada saat arus mencapai nilai maksimum.

\section{Penentuan ITP}

Penentuan ITP dilakukan dengan membuat perbandingan volume kendaraan terhadap nilai kapasitas hasil mikrosimulasi (V/C Ratio). Rasio ini kemudian digunakan untuk menentukan tingkat ITP berdasarkan Peraturan Menteri Perhubungan No. KM 14 Tahun 2006 tentang kriteria penentuan ITP berdasarkan nilai V/C Rasio (Tabel 2).

Tabel 2. Kriteria Penentuan ITP

\begin{tabular}{cll}
\hline ITP & \multicolumn{1}{c}{ Nilai } & Karakteristik Operasi \\
\hline A & V/C rasio $\leq 0,6$ & Arus Bebas \\
B & V/C rasio $\leq 0,7$ & Arus stabil \\
C & V/C rasio $\leq 0,8$ & Arus stabil \\
D & V/C rasio $\leq 0,9$ & Mendekati arus tidak stabil \\
E & Volume pada kapasitas & Arus tidak stabil \\
\hline
\end{tabular}

\section{HASIL DAN PEMBAHASAN}

\section{Geometrik Jalan}

Berdasarkan pengukuran secara langsung di lokasi, Tabel 3 memperlihatkan data geometrik jalan di sekitar Jalan Tengkuruk Permai:

Tabel 3. Data Geometrik Jalan

\begin{tabular}{clcc}
\hline No & \multicolumn{1}{c}{ Nama Ruas Jalan } & Lebar $(\mathrm{m})$ & Tipe \\
\hline 1 & Jl. Tengkuruk Permai & 9,8 & $6 / 2 \mathrm{D}$ \\
2 & Jl. Sultan M Badaruddin II & 8 & $6 / 2 \mathrm{D}$ \\
3 & Jl. Palembang Darussalam & 10,5 & $6 / 2 \mathrm{D}$ \\
4 & Jl. Pasar 16 Ilir & 13 & $6 / 2 \mathrm{UD}$ \\
\hline
\end{tabular}

Pada Jalan Tengkuruk Permai, dari 6 (enam) lajur hanya 2 (dua) lajur yang berfungsi, sedangakan 4 (empat) lajur lainnya digunakan untuk terminal angkutan kota dan parkir badan jalan. Jalan Pasar 16 Ilir hanya berfungsi 2 (dua) lajur sedangkan sisanya digunakan oleh pedagang kaki lima dan parkir sepeda motor. Jalan Sultan Mahmud Badaruddin II dan Jalan Palembang Darussalam masih berfungsi dengan baik. Gambar 3 memperlihatkan penampang melintang Jalan Tengkuruk Permai, dan Gambar 4 memperlihatkan visualisasi kondisinya.

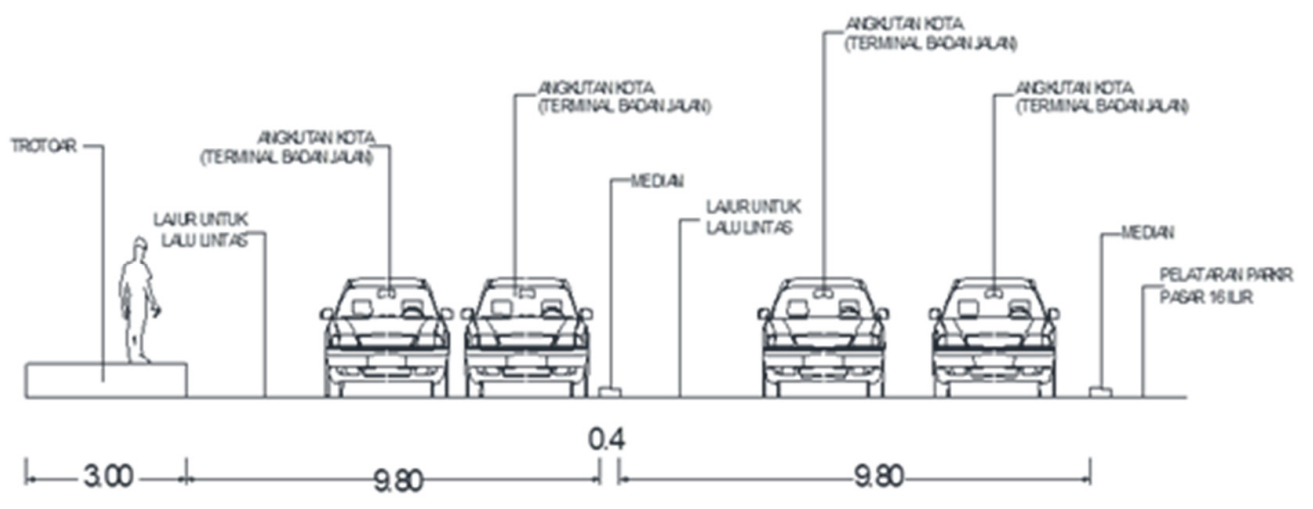

Gambar 3. Penampang melintang Jalan Tengkuruk Permai

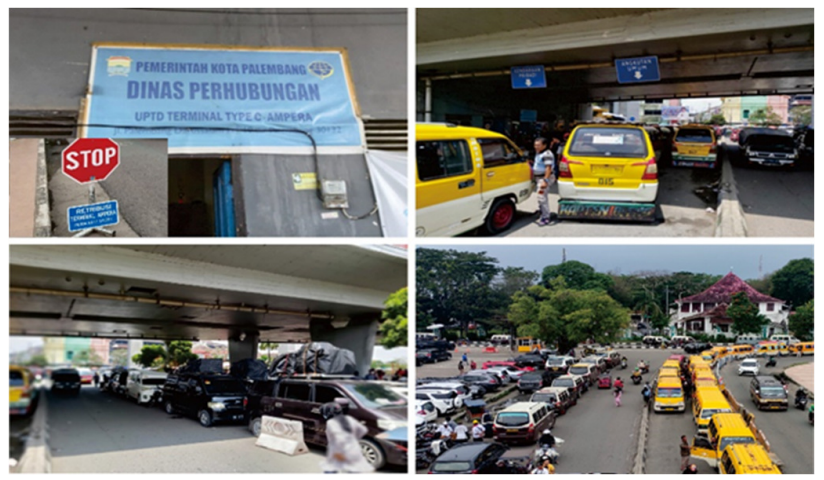

Gambar 4. Visualisasi Jalan Tengkuruk Permai 


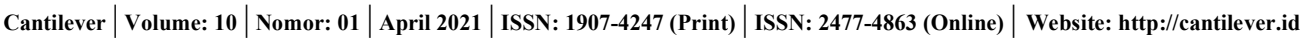

Taharudin, dkk. | Analisis Kinerja Jalan Tengkuruk Permai dengan Mikrosimulasi Pemindahan Terminal dan Parkir Badan Jalan

\section{Volume Kendaraan}

Berdasarkan analisis volume kendaraan, Tabel 4 memperlihatkan volume kendaraan jam puncak.

Tabel 4. Volume Kendaraan Jam Puncak

\begin{tabular}{|c|c|c|c|c|}
\hline \multirow{2}{*}{$\begin{array}{l}\text { No } \\
\text { Arus }\end{array}$} & \multirow{2}{*}{ Arah Tujuan } & \multicolumn{2}{|c|}{$\begin{array}{l}\text { Jumlah Kendaraan } \\
\text { (buah/jam) }\end{array}$} & \multirow{2}{*}{$\begin{array}{c}\text { Jumlah } \\
\text { Kendaraan } \\
\text { (smp/jam) }\end{array}$} \\
\hline & & $\begin{array}{c}\text { Mobil } \\
\text { Penumpang }\end{array}$ & Motor & \\
\hline 1 & $\begin{array}{l}\text { J1. Tengkuruk } \\
\text { Permai Jalur } 1\end{array}$ & 909 & 190 & 956,5 \\
\hline 2 & $\begin{array}{l}\text { Jl. Sultan M. } \\
\text { Badaruddin II }\end{array}$ & 129 & 44 & 140 \\
\hline 3 & $\begin{array}{l}\text { Jl. Tengkuruk } \\
\text { Permai Jalur } 2\end{array}$ & 953 & 266 & 1019,5 \\
\hline 4 & Jl. Pasar 16 Ilir & 162 & 78 & 181,5 \\
\hline
\end{tabular}

\section{Kecepatan Kendaraan}

Pemodelan Vissim tidak mengenal kecepatan tunggal untuk masing-masing jenis kendaraan, tetapi menggunakan distribusi kecepatan bebas kendaraan (free flow speed) hasil pengukuran pada kondisi off peak (lengang). Kecepatan bebas kendaran (free flow speed) motor minimum 16,10 km/jam dan maksimum 38,64 km/jam. Kecepatan bebas (free flow speed) kendaraan penumpang minimum 16,10 $\mathrm{km} / \mathrm{jam}$ dan maksimum 33,81 km/jam. Distribusi kecepatan di Jalan Tengkuruk Permai disajikan dalam Tabel 5.

Tabel 5. Distribusi Kecepatan Bebas Kendaraan

\begin{tabular}{cccc}
\hline No & $\begin{array}{c}\text { Interval } \\
\text { Kecepatan } \\
(\mathrm{km} / \mathrm{jam})\end{array}$ & \multicolumn{2}{c}{ Frekuensi Komulatif } \\
\cline { 3 - 4 } & & $\begin{array}{c}\text { Kendaraan } \\
\text { Penumpang }\end{array}$ & Motor \\
1 & $16-17$ & 0,07 & 0,05 \\
2 & $17-18$ & 0,35 & 0,13 \\
3 & $18-19$ & 0,35 & 0,13 \\
4 & $19-20$ & 0.53 & 0,28 \\
5 & $20-21$ & 0,77 & 0,35 \\
6 & $21-22$ & 0,77 & 0,35 \\
7 & $22-23$ & 0,85 & 0,53 \\
8 & $23-24$ & 0,85 & 0,53 \\
9 & $24-25$ & 0,88 & 0,70 \\
10 & $25-26$ & 1,00 & 0,75 \\
11 & $26-27$ & & 0,75 \\
12 & $27-28$ & & 0,87 \\
13 & $28-29$ & & 0,90 \\
14 & $29-30$ & & 0,90 \\
15 & $30-31$ & & 0,92 \\
17 & $31-32$ & & 0,92 \\
18 & $32-33$ & & 0,98 \\
19 & $33-34$ & & 0,98 \\
20 & $34-35$ & & 1,00 \\
21 & $35-36$ & & \\
\hline
\end{tabular}

\section{Parkir Badan Jalan}

Parkir badan jalan di Jalan Tengkuruk Permai menggunakan 2 (dua) lajur ke arah MONPERA. Parkir badan dengan posisi pararel (tidak menyudut) terdiri dari angkutan kota, mobil penumpang, pangkalan ojek dan angkutan sewa. Akumulasi maksimum parkir badan jalan sebesar 68 kendaraan penumpang dan 97 motor terjadi pukul 16.00-16.14 WIB. Distribusi durasi parkir ditampilkan dalam Tabel 6.

Tabel 6. Distribusi Durasi Parkir Badan Jalan

\begin{tabular}{cccc}
\hline \multirow{2}{*}{ No } & \multirow{2}{*}{$\begin{array}{c}\text { urasi Parkir } \\
\text { (jam) }\end{array}$} & \multicolumn{2}{c}{ Frekuensi Komulatif } \\
\cline { 3 - 4 } & $0-1$ & Kendaraan Penumpang & Motor \\
\hline 1 & $1-2$ & 0,39 & 0,56 \\
2 & $2-3$ & 0,70 & 0,87 \\
3 & $3-4$ & 0,88 & 0,98 \\
4 & $4-5$ & 0,99 & 0,99 \\
5 & 1,00 & 1,00 \\
\hline
\end{tabular}

\section{Terminal Angkutan Kota}

Terminal angkutan kota menggunakan 2 (dua) lajur Jalan Tengkuruk Permai ke arah jembatan Ampera dan merupakan terminal resmi dengan adanya pembayaran retribusi dan kantor operasional. Akumulasi maksimum terjadi pukul 16.00-16.14 WIB sebesar 39 kendaraan yang berjenis Suzuki Carry. Penjadwalan angkutan kota tidak dilakukan dan waktu tunggunya berdasarkan keterisian penumpang. Tabel 7 menyajikan distribusi waktu tunggu angkutan kota.

Tabel 7. Distribusi Waktu Tunggu Angkutan Kota

\begin{tabular}{ccc}
\hline No & Waktu Tunggu (jam) & Frekuensi Komulatif \\
\hline 1 & $0-1$ & 0,53 \\
2 & $1-2$ & 0,62 \\
3 & $2-3$ & 0,80 \\
4 & $3-4$ & 0,91 \\
5 & $4-5$ & 0,99 \\
6 & $5-6$ & 1,00 \\
\hline
\end{tabular}

\section{Pelataran Parkir Pasar 16 Ilir}

Pelataran parkir mempunyai 213 SRP kendaraan penumpang ukuran $2,5 \mathrm{~m} \times 5 \mathrm{~m}$ dan 178 SRP motor ukuran $0,7 \mathrm{~m} \mathrm{x} 2 \mathrm{~m}$. Akumulasi maksimum 227 kendaraan penumpang dan 176 motor. Berdasarkan data tersebut Indeks Parkir kendaraan penumpang $106,57 \%$ dan motor 98,87\%. Akumulasi parkir kendaraan penumpang telah melewati jumlah SRP, sehingga kendaraan parkir ditempatkan di jalur sirkulasi. Distribusi durasi parkir di pelataran parkir Pasar 16 Ilir tersaji dalam Tabel 8.

Tabel 8. Distribusi Durasi Parkir di Pelataran Parkir

\begin{tabular}{cccc}
\hline \multirow{2}{*}{ No } & $\begin{array}{c}\text { Durasi } \\
\text { Parkir } \\
(\text { jam })\end{array}$ & Kendaraan Penumpang & Motor \\
\cline { 3 - 4 } & $0-1$ & 0,45 & 0,61 \\
1 & $1-2$ & 0,67 & 0,77 \\
2 & $2-3$ & 0,76 & 0,84 \\
3 & $3-4$ & 0,85 & 0,89 \\
4 & $4-5$ & 0,88 & 0,93 \\
5 & $5-6$ & 0,93 & 0,95 \\
6 & $6-7$ & 0,96 & 0,99 \\
7 & $7-8$ & 1,00 & 1,00 \\
8 & & & \\
\hline
\end{tabular}




\section{Pemodelan Mikrosimulasi Vissim}

\section{Pemodelan Kondisi Eksisting}

Pemodelan yang dibangun adalah kondisi eksisting dan skenario pemindahan terminal dan parkir badan jalan ke gedung parkir 3 (tiga) lantai beserta sirkulasinya. Model mikrosimulasi kondisi eksisting dibangun dengan menggabungkan model jaringan jalan, terminal angkutan kota, parkir badan jalan, pelataran parkir Pasar 16 Ilir berserta sirkulasi eksistingnya. Parameter yang dimasukkan adalah volume dan komposisi kendaraan, distribusi kecepatan tiap jenis kendaraan, volume dan distribusi durasi parkir, volume dan distribusi waktu tunggu angkutan kota, dan perilaku berkendara pada kondisi eksisting.

Proses kalibrasi dan validasi diperlukan agar model yang dibangun mendekati kondisi sebenarnya. Tabel 9 memperlihatkan hasil uji kalibrasi dan validasi berdasarkan rasio volume kendaraan.

Tabel 9. Hasil Uji Kalibrasi dan Validasi

\begin{tabular}{lccccc}
\hline No & Ruas Jalan & $\begin{array}{c}\text { Volume } \\
\text { Hasil } \\
\text { Pencacahan } \\
\text { (smp) }\end{array}$ & $\begin{array}{c}\text { Volume } \\
\text { luaran } \\
\text { Vissim } \\
\text { (smp) }\end{array}$ & $\begin{array}{c}\text { Rasio } \\
(\%)\end{array}$ & GEH \\
\hline 1 & $\begin{array}{l}\text { Jl. Tengkuruk } \\
\text { Permai }\end{array}$ & 1019,50 & 1032,11 & 98.78 & 0.39 \\
\hline
\end{tabular}

Rasio volume kendaraan hasil pencacahan di lokasi penelitian terhadap volume luaran mikrosimulasi Vissim telah melampaui angka 75\% dan nilai GEH kurang dari 5 (Tabel 9). Nilai-nilai tersebut menunjukkan model valid (Tabel 1).

Model mikrosimulasi yang telah valid dijalankan selama 3600 detik untuk mendapatkan data luaran kecepatan $(\mathrm{km} / \mathrm{jam})$, volume (smp) dan kerapatan $(\mathrm{smp} / \mathrm{km})$ yang stabil pada titik pantau (data collection points) di Jalan Tengkuruk Permai. Nilai kerapatan yang diperolah pada proses ini merupakan gabungan semua jenis kendaraan yang dihitung secara komputerisasi. Data luaran yang diperoleh melalui menu evaluation link segment result ditransfer ke perangkat lunak Microsoft Exel untuk dilakukan analisis (Tabel 10).

Tabel 10. Luaran Mikrosimulasi Vissim Menu Evaluation Link Segment Kondisi Eksisting

\begin{tabular}{cccc}
\hline No & $\begin{array}{c}\text { Kerapatan } \\
(\mathrm{smp} / \mathrm{km})\end{array}$ & $\begin{array}{c}\text { Kecepatan } \\
(\mathrm{km} / \mathrm{jam})\end{array}$ & Volume $(\mathrm{smp})$ \\
\hline 1 & 73,303442 & 14,808638 & 1085,52 \\
2 & 73,598091 & 14,674294 & 1080,00 \\
3 & 73,929078 & 14,608596 & 1080,00 \\
4 & 73,473304 & 14,66758 & 1077,68 \\
5 & 72,663317 & 14,780498 & 1074,00 \\
6 & 72,282845 & 14,858297 & 1074,00 \\
7 & 71,857466 & 14,889683 & 1069,93 \\
8 & 71,712804 & 14,892738 & 1068,00 \\
9 & 71,879467 & 14,858207 & 1068,00 \\
10 & 71,737421 & 14,822587 & 1063,33 \\
\hline
\end{tabular}

Berdasarkan hubungan arus, kecepatan dan kerapatan ( $\mathrm{q}=\mathrm{vk})$ dimana kecepatan berbanding lurus dengan kerapatan, dibangun grafik hubungan antara kerapatan (sumbu x) dan kecepatan (sumbu y) dengan pendekatan linier (Gambar 5), ekponensial (Gambar 6), dan logaritmik (Gambar 7).

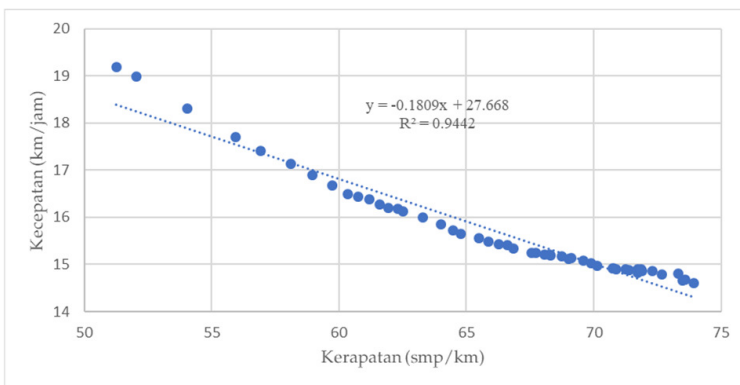

Gambar 5. Hubungan kerapatan dan kecepatan kondisi eksisting dengan pendekatan linier

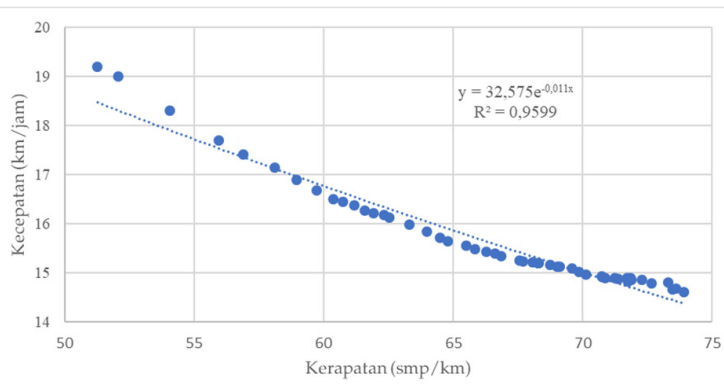

Gambar 6. Hubungan kerapatan dan kecepatan kondisi eksisting dengan pendekatan ekponensial

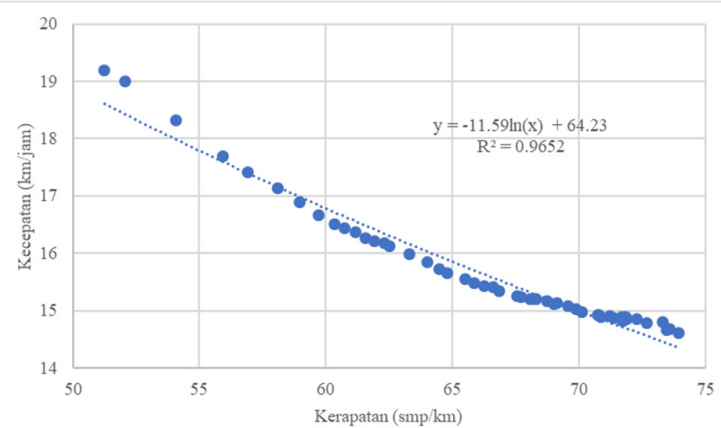

Gambar 7. Hubungan kerapatan dan kecepatan kondisi eksisting dengan pendekatan logaritmik

Dari Gambar 5 s.d Gambar 7, diperoleh model matematis hubungan kerapatan dan kecepatan $\mathrm{Y}=$ $0,1809 x+27,668 \quad\left(R^{2}=0,9442\right), \quad Y=32,575 \mathrm{e}^{-0,011 x}$ $\left(\mathrm{R}^{2}=0,9599\right), \quad$ dan $\quad \mathrm{Y}=-11,59 \ln (\mathrm{x})+64,23 \quad\left(\mathrm{R}^{2}=\right.$ 0,9652 ). Model matematis yang digunakan adalah model yang mempunyai koefesien determinasi terbesar sebagai indikator kemampuan kerapatan mempengaruhi kecepatan yakni model dengan pendekatan logaritmis. Model matematis terpilih kemudian dioperasikan dengan memasukkan variasi kecepatan dimulai angka 0 sampai angka yang 


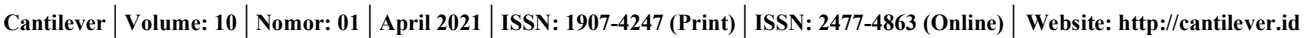

Taharudin, dkk. | Analisis Kinerja Jalan Tengkuruk Permai dengan Mikrosimulasi Pemindahan Terminal dan Parkir Badan Jalan

dibutuhkan untuk mengetahui nilai kecepatan maksimum menuju hasil hampir 0 (asimptotis). Penentuan kapasitas ditentukan dengan menggunakan hubungan antara tiga parameter yakni arus, kecepatan dan kerapatan dimana arus merupakan hasil perkalian kecepatan dan kerapatan $(\mathrm{q}=\mathrm{vk})$.

Berdasarkan persamaan ini diperoleh nilai arus (q) yang merupakan hasil perkalian kecepatan (v) hasil operasi model matematis terpilih dan nilai variasi kerapatan (k). Nilai kapasitas ditetapkan pada saat arus mencapai nilai maksimum yakni $1087,88 \mathrm{smp}$ pada kecepatan $11,57 \mathrm{~km} / \mathrm{jam}$. Tabel 11 menyajikan perhitungan nilai kapasitas jalan. Sedangan Gambar 8 menunjukkan hubungan kecepatan terhadap arus lalu lintas.

Tabel 11. Perhitungan Kapasitas Jalan Kondisi Eksisting

\begin{tabular}{cccc}
\hline No & $\begin{array}{c}\text { Kerapatan } \\
(\mathrm{smp} / \mathrm{km})\end{array}$ & $\begin{array}{c}\text { Kecepatan }(\mathrm{km} / \mathrm{jam}) \\
\mathrm{y}=-\begin{array}{c}11,59 \ln (\mathrm{x})+ \\
64,23\end{array}\end{array}$ & $\begin{array}{c}\text { Arus (smp/jam) } \\
\mathrm{q}=\mathrm{xy}\end{array}$ \\
\hline 1 & 0 & 0,00 & 0,00 \\
2 & 10 & 37,54 & 375,43 \\
3 & 20 & 29,51 & 590,19 \\
4 & 30 & 24,81 & 744,30 \\
5 & 40 & 21,48 & 859,04 \\
6 & 50 & 18,89 & 944,48 \\
7 & 60 & 16,78 & 1006,59 \\
8 & 70 & 14,99 & 1049,30 \\
9 & 80 & 13,44 & 1075,38 \\
10 & 90 & 12,08 & 1086,95 \\
11 & 94 & 11,57 & 1087,88 \\
12 & 100 & 10,86 & 1085,61 \\
13 & 110 & 9,75 & 1072,66 \\
14 & 120 & 8,74 & 1049,16 \\
15 & 130 & 7,82 & 1015,99 \\
16 & 140 & 6,96 & 973,89 \\
17 & 150 & 6,16 & 923,51 \\
18 & 160 & 5,41 & 865,40 \\
19 & 170 & 4,71 & 800,04 \\
20 & 180 & 4,04 & 727,85 \\
\hline
\end{tabular}

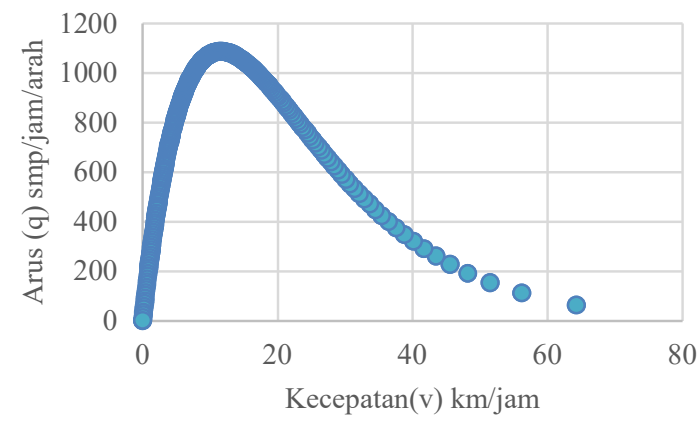

Gambar 8. Hubungan kecepatan dan arus kondisi eksisting

Berdasarkan Tabel 2, penentuan ITP mengacu nilai perbandingan antara volume kendaraan dan kapasitas (V/C Ratio). Penentuan volume kendaraan didasarkan pada dua nilai yakni volume kendaraan berdasarkan pencacahan dan luaran mikrosimulasi Vissim. Perbedaan volume ini disebabkan oleh faktor toleransi kalibrasi. Volume kendaraan hasil pencacahan adalah 1019,5 smp sedangkan rata-rata hasil luaran mikrosimulasi adalah 1032,11 smp. Nilai V/C rasionya adalah 0,937143803 , dan 0,796567636 Tidak ada perbedaan signifikan nilai V/C Ratio berdasarkan 2 (dua) pendekatan tersebut. Mengacu pada Tabel 2, ITP Jalan Tengkuruk Permai pada tingkat E. Proses yang sama dijalankan untuk jalur 2 Jalan Tengkuruk Permai (arah Pasar 16 ke MONPERA dan dihasilkan ITP pada tingkat E.

\section{Pemodelan Kondisi Skenario}

Pemodelan mikrosimulasi kondisi skenario dilakukan dengan mengkombinasikan secara bersamaan skenario pembangunan gedung parkir 3 (tiga) lantai berserta jalan aksesnya, jalur angkutan kota, Jalan Tengkuruk Permai yang telah bersih tanpa parkir badan jalan dan terminal, jaringan jalan di sekitar lokasi penelitian, pengaturan simpang, dan jalur pejalan kaki. Parameter-parameter yang dimasukkan adalah volume kendaraan jam puncak, distribusi durasi parkir, distribusi waktu tunggu angkutan kota, distribusi kecepatan bebas kendaraan (free flow speed) dan perilaku berkendara hasil mikrosimulasi base model yang telah valid. Model dijalankan selama 3600 detik. Proses analisis yang sama dilakukan seperti pemodelan kondisi eksisting. Tabel 12 memperlihatkan luaran mikrosimulasi Vissim.

Tabel 12. Luaran Mikrosimulasi Vissim Menu Evaluation Link Segment Kondisi Simulasi

\begin{tabular}{cccc}
\hline No & $\begin{array}{c}\text { Kerapatan } \\
(\mathrm{smp} / \mathrm{km})\end{array}$ & $\begin{array}{c}\text { Kecepatan } \\
(\mathrm{km} / \mathrm{jam})\end{array}$ & Volume (smp) \\
\hline 1 & 52,16555 & 27,007683 & 1408,87 \\
2 & 51,809294 & 27,185034 & 1408,44 \\
3 & 49,768518 & 28,299766 & 1408,44 \\
4 & 49,138015 & 28,658217 & 1408,21 \\
5 & 48,770557 & 28,704878 & 1399,95 \\
6 & 48,98796 & 28,577489 & 1399,95 \\
7 & 49,356513 & 28,364096 & 1399,95 \\
8 & 49,634293 & 28,143164 & 1396,87 \\
9 & 49,91244 & 27,878186 & 1391,47 \\
10 & 50,25609 & 27,687556 & 1391,47 \\
\hline
\end{tabular}

Grafik hubungan kerapatan dan kecepatan kondisi skenario dengan pendekatan logaritmik yang mempunyai koefesien determinasi $\left(\mathrm{R}^{2}\right)$ terbesar dibandingkan pendekatan linier dan ekponensial (Gambar 9). Perhitungan kapasitas jalan kondisi simulasi tercantum dalam Tabel 13, dan hubungan kecepatan dan arus kondisi skenario tercantum dalam Gambar 10. Berdasarkan Tabel 13 dan Gambar 10, diperoleh kapasitas 2295,15 $\mathrm{smp} / \mathrm{jam} / \mathrm{arah}$ pada kecepatan 11,65 km/jam. Volume kendaraan hasil pencacahan adalah 1019,5 smp dan volume kendaraan rata-rata luaran simulasi adalah 1034,11. Sehingga, V/C rasio adalah 0,444197547 dan 0,450563144. Tidak ada perbedaan signifikan nilai V/C Rasio berdasarkan 2 
pendekatan tersebut. Mengacu pada Tabel 2, kinerja Jalan Tengkuruk Permai kondisi skenario berada pada tingkat A. Proses yang sama dijalankan untuk jalur 2 (arah Pasar 16 Ilir ke Monpera) dan dihasilkan ITP pada tingkat A.

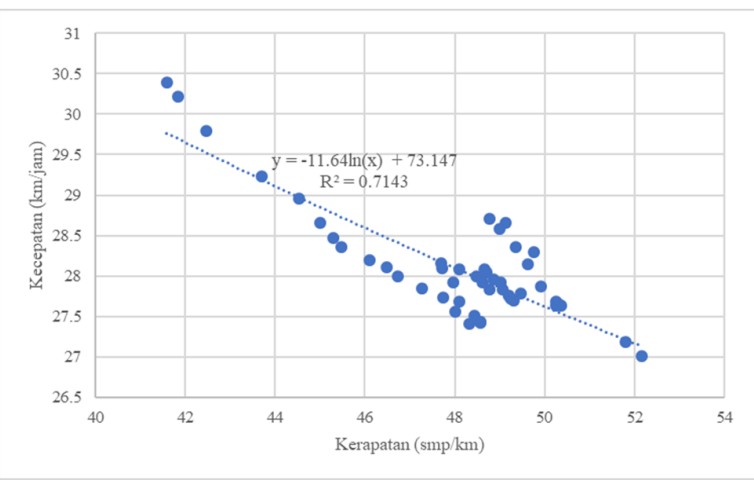

Gambar 9. Hubungan kerapatan dan kecepatan kondisi skenario

Tabel 13. Perhitungan Kapasitas Jalan Kondisi Simulasi

\begin{tabular}{cccc}
\hline No & $\begin{array}{c}\text { Kerapatan } \\
(\mathrm{smp} / \mathrm{km})\end{array}$ & $\begin{array}{c}\text { Kecepatan }(\mathrm{km} / \mathrm{jam}) \\
\mathrm{y}=-11,64 \ln (\mathrm{x})+73,147\end{array}$ & $\begin{array}{c}\text { Arus (smp/jam) } \\
\mathrm{q}=\mathrm{xy}\end{array}$ \\
\hline 1 & $\mathrm{x}$ & 0,00 & 0,00 \\
2 & 0 & 46,34 & 463,45 \\
3 & 10 & 38,28 & 765,53 \\
4 & 20 & 33,56 & 1006,71 \\
5 & 30 & 30,21 & 1208,34 \\
6 & 40 & 27,61 & 1380,55 \\
7 & 50 & 25,49 & 1529,33 \\
8 & 60 & 23,69 & 1658,62 \\
9 & 70 & 22,14 & 1771,22 \\
10 & 80 & 20,77 & 1869,23 \\
11 & 90 & 19,54 & 1954,28 \\
12 & 100 & 18,43 & 2027,67 \\
13 & 110 & 17,42 & 2090,47 \\
14 & 120 & 16,49 & 2143,56 \\
15 & 130 & 15,63 & 2187,68 \\
16 & 140 & 14,82 & 2223,48 \\
17 & 150 & 14,07 & 2251,52 \\
18 & 160 & 13,37 & 2272,27 \\
19 & 170 & 12,70 & 2286,18 \\
20 & 180 & 12,07 & 2293,61 \\
21 & 190 & 11,47 & 2294,92 \\
22 & 200 & 10,91 & 2290,40 \\
23 & 210 & 10,37 & 2280,34 \\
24 & 220 & 9,85 & 2244,57 \\
25 & 230 & 9,35 & \\
\hline & 240 & & \\
& & & \\
\hline
\end{tabular}

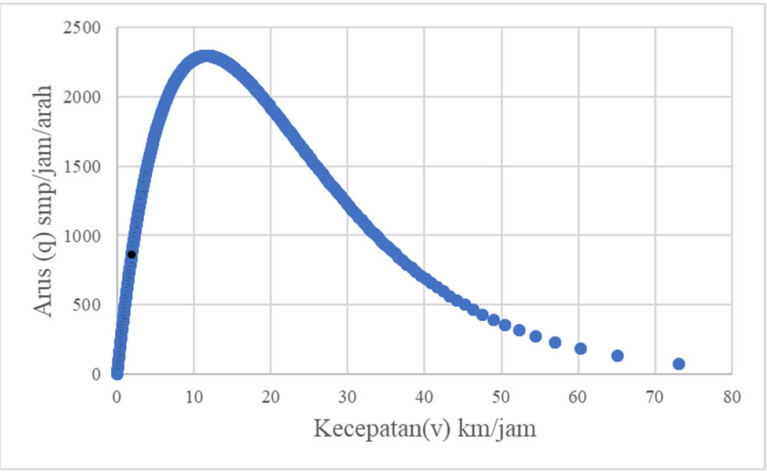

Gambar 10. Hubungan kecepatan dan arus kondisi skenario

\section{KESIMPULAN}

Berdasarkan hasil mikrosimulasi Vissim dan analisis luarannya, dapat disimpulkan bahwa:

a. Skenario penanganan pemindahan Terminal Angkutan Kota Ampera dan parkir badan jalan ke pelataran parkir Pasar 16 Ilir dapat dilakukan dengan pembangunan gedung parkir 3 (tiga) lantai, pengadaan lajur khusus angkutan kota dan merubah sirkulasinya.

b. Berdasarkan analisis luaran menu link segment evaluation model mikrosimulasi Vissim pada kondisi skenario pemindahan terminal angkutan kota dan parkir badan jalan ke gedung parkir 3 (tiga) lantai di pelataran parkir Pasar 16 Ilir, berupa kecepatan (speed), kerapatan (density) dan volume, kinerja Jalan Tengkuruk Permai dengan parameter ITP meningkat dari tingkat $\mathrm{E}$ ke A. Kapasitas mengalami peningkatan dari 1087,88 smp/jam/arah menjadi $2295,15 \mathrm{smp} / \mathrm{jam} / \mathrm{arah}$, atau meningkat sebesar $110,97 \%$.

\section{UCAPAN TERIMA KASIH}

Terima kasih saya ucapkan kepada Laboratorim Transportasi Fakultas Teknik Universitas Sriwijaya.

\section{REFERENSI}

Peraturan Menteri Perhubungan No. KM 14 Tahun 2006 tentang kriteria penentuan ITP berdasarkan nilai V/C Rasio. (2006). Jakarta: Kementerian Perhubungan.

Departemen_Permukiman_dan_Prasarana_Wilayah. (2004). Pédoman Survei Pencacahan Lälu Lintas dengan Cara Manual.

Małecki, K. (2018). A computer simulation of traffic flow with on-street parking anddrivers' behaviour based on cellular automata and a multi-agentsystem. Journal of Computational Science, 28, 32-42.

Munawar, A. \& Yulianto, R. A. (2017). Penentuan Kapasitas Jalan Bebas Hambatan dengan Aplikasi Perangkat Lunak Vissim. Jurnal Transportasi, 17(2), 123-132.

Munawar, A. (2011). Speed and Capacity for Urban Roads, Indonesian Experience. Procedia - Social and Behavioral Sciences, 16, 382-387.

NCHRP. (2014). NCHRP Report 765:Analytical Travel Forecasting Approaches for Project-Level Planning and Design. TRB.

Portilla, A. I, Orena, B. A., Berodia, J. L. M., \& Diaz, F. J. R. (2009). Using $\mathrm{M} / \mathrm{M} /$ infinite queuing model in onstreet parking manoeuvres. Journal of Transportation Engineering, 135, 527-535.

Pribadi, O. S. (2017). engkinian Manual Kapasitas Jalan Indonesia Segmen Jalan Perkotaan dengan Traffic Microsimulation. Yogyakarta: UGM.

Sugiarto \& Limanoond, T. (2013). mpact of On-street Parking on Urban Arterial Performance: A Quantitative Study on Travel Speed and Capacity Deterioration. Aceh International Journal of Science and Technology, 6369. 